\title{
Produção coletiva de webnovelas: um estudo sobre metodologias dialógicas e participativas ${ }^{1}$
}

Maria Isabel Rodrigues Orofino

Professora do Programa de Mestrado em Comunicação e Práticas de Consumo PPGCOM/ ESPM SP

E-mail: iorofino@espm.br

Resumo: Este texto relata uma experiência de Comunicação e Educação que resultou na produção e veiculação, no YouTube, de cinco webnovels realizadas por crianças de classe popular moradoras de uma comunidade na periferia urbana da cidade de São Paulo. Com esta iniciativa, buscamos verificar a hipótese teórico-metodológica da mídia-educação enquanto metodologia colaborativa na prática escolar transformadora. Questionam-se as denúncias que reduzem as tecnologias a um fenômeno meramente de mercado. Defende-se o uso das tecnologias digitais com as crianças como uma questão de direito à inclusão digital, de criatividade e de produção cultural coletia. Apresentamos uma reflexão de caráter metodológico sobre uma pesquisa participante feita com trinta crianças em uma escola pública.

Palavras-chave: Mídia; educação; crianças; webnovelas; mídia-educação.
Abstract: This paper reports an experience of Communication and Education that resulted in the production and broadcasting on Youtube of five web series by children from a poor community in the periphery of São Paulo. With this work, we aim to verify the theoretical-methodological hypothesis of media education as a collaborative methodology in the transformative educational practice. We question the complaints that reduce the technologies to a mere market phenomenon. We defend the use of digital technologies with the children as a question of digital inclusion, of creativity and collective cultural production rights. We present a methodological reflection about a participant research conducted with 30 children from a public school.

Keywords: Media; education; children; webseries; media education.

\section{CARACTERIZAÇÃO DO ESTUDO, EXPERIÊNCIA E REFLEXÃO TEÓRICA PROPOSTA}

O trabalho que apresentamos neste artigo refere-se a uma pesquisa que se encontra em desenvolvimento (work in progress). A mesma teve início no ano de 2010, a partir de nossa participação em um grupo vinculado ao Programa de Pós-graduação em Comunicação e Práticas de Consumo, em um projeto 
comunicação \& educação • Ano XV|l| • número 1 • jan/jun 2013

que toma como objeto as relações entre comunicação e consumo com base na telenovela. O grupo definiu interesses particulares para explorar tais relações.

$\mathrm{O}$ nosso recorte em particular tomou como foco as crianças enquanto sujeitos da observação. Portanto, partimos de uma pesquisa de recepção de telenovela para conjuntamente realizarmos uma iniciativa de mídia-educação.

Assim, fizemos uma pesquisa de recepção de telenovela por parte do público infantil. Trabalhamos com um grupo de 36 crianças, estudantes de uma escola pública na cidade de São Paulo, em um de seus bairros populares, pelo período de um semestre letivo. Nossa permanência na escola, para a realização da pesquisa de recepção, desencadeou uma série de atividades e vínculos com a direção e os professores.

Foram realizadas: (i) palestras de formação com o corpo docente; (ii) diálogos sobre políticas de comunicação para a escola (junto à direção); (iii) diálogos sobre produção criativa junto ao grupo de comunicação da escola; (iv) diálogos com as POIE (Professor Orientador de Informática na Educação), em conjunto com o trabalho em sala de aula com a professora regente da $4^{\mathrm{a}}$ série.

O pesquisador de comunicação que estiver em relação de pesquisa com a escola pode e deve cooperar com as mediações escolares. Estas mediações escolares, de que fala Guillermo Orozco-Gomez, de fato, já acontecem na escola. Porém, a presença do comunicador na escola qualifica esta discussão de maneira diferenciada; pois, uma vez que se trata da presença de um especialista no tema, o mesmo pode oferecer uma série de contribuições a este debate junto às escolas. Assim, as contribuições que o comunicador oferece à educação são amplas, variadas e reservam múltiplas possibilidades.

Neste paper vamos buscar demonstrar os resultados de um trabalho que nos encoraja a levar adiante nossa defesa de que a mídia-educação pode e deve ser pensada enquanto uma metodologia. Isto é, enquanto uma nova forma de educar.

Portanto, temos o entendimento de que a mídia-educação não é mais uma disciplina a competir com tantas outras por um espaço na grade curricular. A mídia-educação é uma metodologia, uma nova forma de educar, pois ela toca todas as disciplinas. Todos os professores, de fato, são educomunicadores.

Nas páginas seguintes vamos apresentar algumas contribuições parciais à compreensão das possibilidades de termos na mídia-educação uma metodologia de trabalho na educação transformadora, pois, com ela, de fato, alcançamos uma forma de mediação escolar que permite ativar a reflexividade na produção de conhecimento com as crianças e os jovens por meio de múltiplas plataformas e formas de intervenção.

\section{PERGUNTAS CENTRAIS OU A ETERNA CURIOSIDADE EPISTEMOLÓGICA}

O problema motivador da pesquisa se estruturou em três lugares de observação: o consumo e os usos das novas tecnologias digitais por crianças de 
classes populares; a recepção de telenovela e a transmedialidade por parte das crianças; e a possibilidade da observação participante no espaço escolar por parte do comunicador. Com isso, defendemos um olhar sobre a mídia-educação que é transdiciplinar e multimetodológico, um lugar necessariamente convergente, integrador e, portanto, transformador, não apenas inovador.

Sob o ponto de vista da teoria, também trabalhamos de modo transdisciplinar. Contamos com os aportes dos estudos de comunicação e da pesquisa de recepção; dos estudos que enfatizam o receptor ativo e, mais do que isso, o prossumidor: que se trata de uma categoria emergente, e por isso mesmo uma categoria aberta às críticas. Mas defendemos que há aí um novo lugar de observação que merece toda a nossa atenção. Este receptor ativo não apenas expressa variadas competências culturais e subjetivas diante do texto midiático, como também sabe manusear as tecnologias com agilidade e destreza. E, na medida em que lê, também responde, produz novas textualidades, sobretudo com as novas plataformas digitais e redes sociais.

Para problematizar tais questões buscamos uma série de contribuições teóricas no âmbito de uma teoria crítica da cultura. Para uma teoria da cultura propriamente, tomamos o trabalho de Raymond Williams, um estudioso das formas culturais.

Como destacamos anteriormente ${ }^{2}$, muitos autores defendem a ideia de que a cultura precisa ser compreendida menos enquanto oposições binárias e muito mais pela ideia de teia de complexidades, de trama.

Dentre os autores que buscam problematizar a cultura a partir de uma perspectiva de trama ou teia de complexidades, está a obra de Raymond Williams. Nela está a sua grande contribuição com os escritos que fez sobre a indústria cultural e como esta articula o popular e o erudito, em uma diversidade de dimensões ou níveis que operam efetivas mudanças culturais.

Segundo Martín-Barbero, Williams é o autor da imagem metodológica mais aberta e precisa que temos até hoje: aquela que respeita a emergência do popular como cultura a partir das práticas, e para defini-las ele cria uma tipologia das formações culturais em três níveis: (1) o dominante; (2) o residual e (3) o emergente. Juntamente com o trabalho de Raymond Williams, sempre nos interessaram também os teóricos dos estudos culturais da Escola de Birmingham (Hall, Morley e, de certa forma, Silverstone).

Lançamos um olhar atento também ao trabalho dos autores latino-americanos no campo da comunicação, cultura e mediações. Sobretudo o de Jesús Martín-Barbero e Guillermo Orozco Gomes. Na obra de Jesús Martín-Barbero, como destacamos anteriormente ${ }^{3}$, encontramos o recente debate em torno de uma perspectiva das mediações na América Latina - sobretudo a partir da contribuição oferecida pela obra de Jesús Martín-Barbero - que propõe um modelo compreensivo integrador entre os processos de produção, do produto e da audiência.

Um avanço importante proposto pelos autores latino-americanos é justamente o de tentar superar esta fragmentação a partir de uma compreensão
2. OROFINO, Maria Isabel. Mediações na produção de teleficção: um estudo sobre o Auto da Compadecida. Porto Alegre: EdiPUC-RS, 2006.

3. OROFINO, Maria Isabel. Mídia e mediação escolar: pedagogia dos meios, participação e visibilidade. São Paulo: Cortez, 2005. 
comunicação \& educação • Ano XV|l| • número 1 • jan/jun 2013

da comunicação enquanto processo sócio-histórico, problematizado a partir da cultura, propondo um novo deslocamento, qual seja: o da recepção às mediações.

E então buscamos aportes teóricos ainda no âmbito da mídia-educação. Neste caso há também um longo percurso já trilhado na América Latina, mas a nossa ênfase foi na localização de estudos que valorizem a participação das crianças na produção de contranarrativas de libertação. Isso significa pensar a mídia-educação como metodologia para a educação libertadora, o que nos leva a Paulo Freire e todos os autores vinculados a uma pedagogia dialógica, problematizadora e emancipadora. Defende-se que a educação é, em primeiro lugar, um ato político, uma questão de direito. E a partir daí pensa-se, então, em tudo o mais que lhe compete, como: o desenvolvimento da autonomia, da criatividade, da participação, da cooperação, da consciência, da inteligência, da sensibilidade.

Detivemo-nos também em identificar as contribuições oferecidas pelo trabalho do grupo vinculado à ECA-USP nos estudos da Comunicação e Educação, que aqui merece destaque: Maria Aparecida Baccega, Ismar de Oliveira Soares, Adilson Citelli, Maria Immacolata Lopes, Roseli Figaro, entre outros. Destacamos também nosso interesse pelo trabalho de David Buckingham, Ellen Seiter e Sonia Livingstone, para uma reflexão sobre mídia e infância.

\section{OBSERVAÇÃO PARTICIPANTE OU O DESAFIO DA PESQUISA DE CAMPO}

Sair a campo exige do pesquisador a pré-disposição de se distanciar do seu lugar, de sua zona de conforto das salas da universidade, laboratórios e escritórios e, para enfrentar o tempo, o espaço, o clima, das intempéries, do trânsito, do desconhecido, do estranho, do Outro.

A pesquisa de campo, de caráter etnográfico, é, como identificou a Profa. Rute Cardoso, uma aventura. Nosso campo fica nas bordas da grande cidade, nas extremidades das margens de uma das maiores megalópoles do planeta: a cidade de São Paulo, com uma população em torno de 20 milhões de habitantes. A comunidade do Morro Grande, próximo à Freguesia do Ó, onde trabalhamos, é desenhada por vielas estreitas de barro cru, com casas - quase todas - sem pinturas nas paredes. Casas modestas, sem muros, com cercas de arames frouxos.

A escola é bonita, nova, com apenas quatro anos de atividade. Em grande medida ouvimos denúncias com relação à escola pública. Nossa impressão foi muito positiva nesse sentido. A escola que visitamos tinha uma excelente instalação, uma excelente equipe (do porteiro ao diretor). Uma equipe solidária, cooperativa, consciente, responsável. Foram tantas as vezes que me deparei com relatos de denúncia com relação à escola, o abandono da gestão pública, a falta de recursos, a desmotivação dos professores. 
Nossa etnografia se estendeu pelo período de um semestre letivo. Em termos metodológicos buscamos um diálogo com o trabalho de Carlos Rodrigues Brandão, Michel Thiollent e Antunes. A pesquisa participante e a pesquisa-ação são, para a prática da Educomunicação e da Mídia-Educação, uma metodologia fundamental. Nossa etnografia do espaço escolar esteve articulada a uma metodologia da pesquisa participante, o que nos permitiu um vínculo explícito com a política escolar de ação cultural e ação midiática naquela escola.

Os vínculos se explicitaram por meio de consultorias junto à direção com relação às políticas de comunicação da escola, com uma intervenção na constituição de momentos de diálogo e palestras com os professores sobre a presença da mídia na vida de todos nós (educadores, profissionais e educandos) e, também, com a realização do trabalho de produção de webnovelas com a turma da $4^{\text {a }}$ série.

Nesta última etapa utilizamos uma série de técnicas de pesquisa, como a produção de redações a partir de temas geradores identificados pelas próprias crianças, a elaboração de storyboards, a redação de roteiros, a decupagem dos roteiros, a produção propriamente, a gravação, a edição, a apresentação na escola, a veiculação, a distribuição e a recepção desse trabalho pelas crianças que participaram da iniciativa.

\section{AS WEBNOVELAS PRODUZIDAS}

Nossa permanência em campo possibilitou a realização de uma experiência de mídia-educação com a produção de cinco episódios de webnovelas. Este trabalho foi uma contrapartida oferecida à escola que nos recebeu pelo período de um semestre para uma pesquisa mais ampla - como destacamos na abertura deste texto - sobre as relações entre comunicação, telenovela, consumo e tecnologias.

O trabalho na escola incluiu a elaboração de palestras para o corpo docente sobre diferentes enfoques a respeito da mídia no conjunto das teorias da comunicação e educação e novas possibilidades de crítica e usos sociais dos meios. Foi realizada de uma atividade de mídia-educação (experiência piloto)

com a mesma turma da pesquisa como atividade inter e transdiciplinar, com foco direcionado aos temas geradores definidos pela própria turma com a qual estávamos trabalhando.

A realização das webnovelas partiu da iniciativa da professora Roberta Duarte, responsável pela $4^{\mathrm{a}}$ série com a qual estávamos trabalhando. A professora partiu de temas geradores, e as crianças criaram redações sobre as seguintes questões: (i) deficiência física; (ii) intolerância; (iii) superação (iv) amizade e (v) amor.

O trabalho envolveu a redação das histórias e posteriormente todas as etapas de produção dos vídeos com criação dos storyboards, para que as crianças pudessem realizar o trânsito da forma escrita para a linguagem visual. 
comunicação \& educação • Ano XV|l| • número 1 • jan/jun 2013

Posteriormente, os roteiros foram criados. E na sequência, a decupagem de produção para definição das locações, figurino, maquiagem, atuação, assistência de direção e assistência de câmera. As gravações foram todas realizadas com uma pequena câmera digital em um sábado, durante todo o dia, nas dependências da própria escola.

O mais interessante a observar foram as referências à telenovela que estávamos estudando naquele momento ${ }^{4}$, em vários aspectos das narrativas construídas pelas crianças. Elas redigiram as redações justamente quando a telenovela estava no ar. Cabe destacar que estas menções não eram reproduções, mas sim recriações que nos permitem compreender como ocorrem os processos de ressignificação.

$\mathrm{Na}$ webnovela sobre o cotidiano de portadores de necessidades especiais há uma narrativa de um cadeirante que supera a sua doença a partir do momento em que sua mãe o visita no hospital. Isto nos permite perceber como funciona a ressignificação da telenovela no imaginário das crianças com as quais trabalhamos, sendo vista como uma narrativa de superação, o que difere da telenovela veiculada. Outra webnovela sobre o amor romântico fez referências à cidade de Paris, justamente quando os personagens da telenovela Viver a vida - Luciana e Miguel - estavam passando a lua de mel nesta cidade. E em uma outra webnovela, sobre o amor entre namorados, as crianças roteirizaram o final da história com um grande casamento, fazendo uma citação explícita ao fato de que "quase toda" telenovela termina com esse tipo de cena.

A realização das webnovelas nos permitiu entender não só as questões de ressignificação do conteúdo da teleficção no imaginário, como a competência cultural da criança com relação a este gênero em particular e sua tradução na cultura brasileira.

\section{SOBRE AS ETAPAS DE PRODUÇÃO DOS VÍDEOS}

O vídeo é uma linguagem híbrida em texto, imagem e som. Seu aspecto articulado em três códigos o torna particular, e este aspecto confere à pedagogia do audiovisual um lugar privilegiado para o desenvolvimento cognitivo e criativo.

Atualmente o vídeo e a TV atravessam grandes transformações para uma nova fase no seu desenvolvimento material. Estamos hoje experienciando as novas possibilidades desencadeadas pela WebTV, o que muda radicalmente

4. Viver a vida - Rede Globo, 2010

5. BARKER, Chris. Televison, Globalization and Cultural Identities. Buckingham/Philadelphia, Penn: Open University Press, 1999. tanto os modos de difusão quanto de produção de linguagens. A velha TV possuía uma trajetória histórica com início a partir do uso e aplicação de tecnologias mecânicas; um segundo momento foi marcado pelo desenvolvimento do sistema eletrônico/analógico e, hoje, os sistemas digitais passam a mudar significativamente as estruturas de produção, difusão e recepção das mensagens audiovisuais. Os sistemas digitais são definidos por Barker ${ }^{5}$ como: 
Produção coletiva de webnovelas - Maria Isabel Rodrigues Orofino

Aqueles que permitem que a informação seja organizada eletronicamente em bytes, em pequenas unidades discretas de informação, que podem ser comprimidas durante a transmissão e descomprimidas na chegada. Isto permite que uma quantidade bem maior de informação possa se deslocar por qualquer conduto dado, seja ele o cabo, satélite ou sinais terrestres (isto também abre zonas do espectro de uso não utilizadas previamente) e em grande velocidade sobre longas distâncias. $\mathrm{Na}$ realidade, o impacto das novas tecnologias em geral e dos sistemas digitais em particular pode ser resumido em termos de velocidade, volume e distância. $\mathrm{O}$ que quer dizer maior informação em maior velocidade em longas distâncias ${ }^{6}$.

Com os usos sociais das tecnologias digitais surgem novos apelos estéticos ligados à convergência tecnológica e às possibilidades de fusão de formas culturais em hipertextos. Neste contexto, as possibilidades criativas com as novas mídias são muito amplas, muito diversificadas.

Nossa metodologia de mídia-educação obedeceu às seguintes etapas de trabalho com a participação das crianças: em primeiro lugar buscamos um diálogo muito próximo e, com a participação da professora Roberta, foi possível fazer a identificação de temas geradores que atendessem às demandas reflexivas das crianças naquele momento. Os temas que emergiram foram: a questão da deficiência física; intolerância; superação; amizade e amor.

Após serem identificados os temas, foram escolhidos os grupos de trabalho. A primeira etapa, de redação criativa, já aconteceu em grupos. Quando as crianças produziram as suas redações coletivas, as mesmas foram lidas e comentadas pela professora. Na sequência as crianças participaram de um debate sobre a presença da mídia na vida de todos nós. Algumas palestras sobre comunicação e cultura aconteceram, identificando inclusive formas culturais, formatos industriais e gêneros narrativos. As crianças passaram a participar então de oficinas de produção. Estas oficinas incluíram atividades como: a criação de storyboards (histórias em quadrinho). Esta etapa é muito interessante porque deflagra um lugar privilegiado de trânsito da linguagem verbal para a visual.

Após o trabalho e a leitura final, com os textos verbais (as redações), partimos para a elaboração de história em quadrinhos. Com os stotyboards prontos, a etapa seguinte foi a de roteirização. Neste momento surgiu a possibilidade de realização de um amplo debate sobre técnica e tecnologia com as crianças. Um debate sobre consumo e usos sociais das tecnologias digitais encontrou também aqui uma ótima oportunidade. Outra etapa de trabalho foi a realização da produção técnica, que exigiu não só providências com a câmera e o microfone, mas também atuação/interpretação, direção geral e de arte, cenografia, trilha sonora, figurino e maquiagem.

$\mathrm{Na}$ etapa de produção consolidou-se a metodologia colaborativa, com as diferentes identificações, por parte das crianças, das múltiplas funções da produção coletiva. Com isso alcançou-se um alto grau de participação e colaboração.

6. BARKER, op. cit., p. 48. 
comunicação \& educação • Ano XV|II • número 1 • jan/jun 2013

As crianças optaram por desempenhar diferentes funções no processo de produção, que foram desde assistência de direção, escolha por desempenhar o papel de ator, atriz, figurante, até maquiagem e figurino (funções estas muito disputadas pelas meninas).

No dia da gravação cada criança exerceu sua função, e os demais colaboravam ora como figurantes, ora como apoio técnico, ou, ainda, como assistentes de produção do filme da outra equipe.

A edição continua acarretando um afunilamento, por isso é preciso experimentar outras iniciativas que contem cada vez mais com o conhecimento de edição das próprias crianças. A apresentação do trabalho aconteceu na escola, na festa de formatura da turma e final de ano. Posteriormente foram copiadas em CD e postadas no YouTube.

\section{ALGUNS RESULTADOS ALCANÇADOS}

Este trabalho nos permitiu alcançar alguns resultados importantes para a pesquisa no campo da comunicação e educação. Vamos destacar alguns deles, compreendendo que são resultados parciais e que modestamente nos podem apontar novos caminhos para a prática da educação transformadora.

Em primeiro lugar, verificamos que a aliança entre duas metodologias valiosas, como o estudo de recepção e a mídia-educação, são etapas complementares e que se articulam. Os estudos de recepção nos possibilitam compreender o universo cultural e midiático das crianças. Além dissso, permitem que o educador note qual é o repertório cultural dos estudantes: a que assistem, como assistem, o que apreciam, o que recusam e como o fazem.

Este estudo nos fez perceber também qual o papel da criança enquanto agente social com competências próprias, que constrói táticas nos usos e apropriações que faz dos meios de comunicação e que, também, apresenta competências na produção de novas narrativas com o uso da linguagem audiovisual.

Foi possível também construir novas referências que contribuam para a superação de uma visão da tecnologia como algo unicamente atrelado ao mercado e aos interesses do consumismo. Verificamos que no Brasil, em particular, ainda há, por um lado, uma política neoliberal cuja ênfase nos usos das tecnologias no espaço escolar parece se justificar muito mais pelos interesses obscuros dos grandes volumes de vendas de equipamentos e seus altos percentuais em comissões, do que propriamente pelo desenvolvimento de novas metodologias que fortaleçam as práticas dos educadores e dos estudantes, bem como suas demandas e formas de narrar e de construir visibilidade para seus discursos.

Assim, defendemos que continua importante investirmos muito mais na formação dos educadores para que transitem com maior liberdade criativa pelo universo dos estudos de comunicação e da mídia. É fundamental estabelecer este diálogo entre o campo da comunicação, com suas práticas e processos, 
Produção coletiva de webnovelas - Maria Isabel Rodrigues Orofino

e o campo da educação, enquanto um lugar da produção criativa e de ação cultural libertadora.

\section{REFERÊNCIAS BIBLIOGRÁFICAS}

BARKER, Chris. Televison, Globalization and Cultural Identities. Buckingham/ Philadelphia, Penn: Open University Press, 1999.

BRANDÃO, Carlos Rodrigues et al. Pesquisa participante. São Paulo: Brasiliense, 1983.

. Repensando a pesquisa-participante. São Paulo: Brasiliense, 1985.

BUCKINGHAM, David. After the death of childhood: growing up in the age of electronic media. Cambridge: Polity, 2000.

- Media Education: literacy, learning and contemporary culture. Cambridge: Polity, 2003.

CITELLI, Adilson. Linguagem e persuasão. São Paulo: Ática, 1993.

FREIRE, Paulo. Pedagogia do oprimido. Rio de Janeiro: Paz e Terra, 1975. Terra, 1976.

Ação cultural para a liberdade e outros escritos. Rio de Janeiro: Paz e

GADOTTI, Moacir; ROMÃO, José Eustáquio. Autonomia da escola: princípios e propostas. São Paulo: Instituto Paulo Freire/Cortez, 1997 (Série Escola Cidadã). et. al. Pedagogia: diálogo e conflito. São Paulo: Cortez, 1985.

GARCÍA CANCLINI, Néstor. Culturas híbridas. São Paulo: Edusp, 1998.

GIDDENS, Anthony. A constituição da sociedade. São Paulo: Martins Fontes, 1989.

As consequências da modernidade. São Paulo. Unesp, 1991.

MARTÍN-BARBERO, Jesús. Dos meios às mediações: comunicação, cultura e hegemonia. Rio de Janeiro: Editora UFRJ. 1987

MORIN, Edgar. Os sete saberes necessários à educação do futuro. São Paulo: Cortez, 2000.

OROFINO, Maria Isabel. Mídia e mediação escolar: pedagogia dos meios, participação e visibilidade. São Paulo: Cortez, 2005.

Mediações na produção de teleficção: um estudo sobre o Auto da Compadecida. Porto Alegre: EdiPUC-RS, 2006.

OROZCO, Guillermo. Mediações escolares e familiares na recepção televisiva. Revista Brasileira de Comunicação, São Paulo, Intercom, 1991. 


$$
\text { comunicação \& educação • Ano XVIII • número } 1 \text { • jan/jun } 2013
$$

- Cultura y Television: de las comunidades de referencia a la produccion de sentido en el processo de la recepcion. México: Universidade Iberoamericana 1992.

THIOLLENT, Michel. Metodologia da pesquisa-ação. São Paulo, Cortez, 1985.

WILLIAMS, Raymond. Television, technology and cultural form. New York: Schocken Books, 1975. 